\title{
CONCEPTS
}

\section{Should Airbag Backpacks Be Standard Avalanche Safety Equipment?}

\author{
Christopher Van Tilburg, $\mathrm{MD}^{1,2}$ \\ ${ }^{1}$ Mountain Clinic, Occupational and Travel Medicine, and Emergency Department, Providence Hood River Memorial Hospital, Hood River, \\ Oregon; ${ }^{2}$ Crag Rats Mountain Rescue, Portland Mountain Rescue, Clackamas County Search and Rescue, Pacific Northwest Search and Rescue, \\ Hood River, Oregon
}

\begin{abstract}
Avalanche airbag backpacks have been shown to be effective at reducing avalanche mortality. However, they are yet to be considered standard avalanche safety equipment, which has long consisted of a transceiver, a shovel, and a probe. This is despite data showing that airbags reduce mortality by decreasing the likelihood of burial. In addition, airbags probably lessen trauma and possibly delay asphyxia. Moreover, the literature suggests airbags reduce mortality at a rate similar to transceivers. For those who work, volunteer, and recreate in avalanche terrain, airbags should be considered standard safety equipment. However, multiple barriers exist for universal adoption, including cost, size, weight, training burden, availability, risk tolerance, and lack of community support and recommendations from professional societies and associations.
\end{abstract}

Keywords: snow burial, beacon, transceiver, emergencies, self-rescue

\section{Introduction}

The avalanche airbag backpack was first patented by German skier Peter Aschauer nearly 4 decades ago. Early inspiration was reportedly based on the experience of forest ranger Josef Hohenester, who found that when he hauled large game on his back, he floated more easily in snow. Aschauer first demonstrated his airbag at the Internationale Fachmesse fur Sportartikel und Sportmode (international trade fair for sporting goods and sportswear) in Munich in 1985. After nearly 4 decades, airbag design and functionality have been refined.

Avalanche airbags work based on the property of particle physics called granular convection. In a flow, particles of larger volume migrate to the top. Airbags increase the volume of users by $150 \mathrm{~L}$ or more and thus assist in keeping the user at the top of avalanche debris.

Airbags are widely available in Europe and North America. Airbags use 2 general systems, inflated by either compressed gas canisters or electronic fans. Canister airbags come in multiple configurations and with

Corresponding Author: Christopher Van Tilburg, MD, PO Box 1556, Hood River, OR 97031; e-mail: vantilburg@gorge.net.

Submitted for publication April 2020.

Accepted for publication May 2021. various gasses, such as air, nitrogen, argon, and carbon dioxide. In some models, compressed air canisters are refillable. Other systems use 1 or 2 single-use disposable canisters. Electronic fan airbags are powered by a rechargeable lithium-ion battery or a capacitor with battery backup. Neither the canister nor the fan system has been demonstrated to be superior in preventing burial. Both add significant weight, bulk, and expense compared to a standard, non-airbag backpack.

The benefits of canister airbags are that they tend to be lighter and less expensive. The downside is that canisters are not easy to refill or replace, are not standard among manufacturers, and can be limited for airline travel and shipping by regulations, especially in North America. For multiple deployments, canisters pose difficulty in terms of practice, rearming an airbag that needs to be used more than once, and sharing extra canisters in groups that use different airbag brands. The addition of extra canisters to a backpack increases both cost and weight.

The benefits of an electronic fan airbag are that multiple deployments and airline transport are simpler. This makes practice easier and less expensive. A potential problem is that they rely on power and electronics, which may be affected by cold temperature and availability of 
power for charging. Fan airbags are also more costly and heavier than canister airbags.

\section{Published Recommendations}

Avalanche airbags are used in backcountry areas around the world. Many organizations have provided recommendations regarding their use. Because of the varied infrastructure, legal, and governmental issues around the world, this review will only examine selected current recommendations in North America.

In 2017, a Wilderness Medical Society (WMS) clinical practice guideline reviewed the avalanche literature, which demonstrated the effectiveness of airbags but did not give a solid recommendation. ${ }^{1}$ The recommendation was twofold:

Travelers entering avalanche terrain should consider using an avalanche airbag. Familiarity and regular practice with airbags is essential. Grade: $1 B$ (strong recommendation, moderate-quality evidence).

Airbag backpacks may or may not provide head and neck protection from trauma. Ungraded: No Recommendation.

Similarly, the International Commission for Alpine Rescue has a recommendation from 2006 that supports airbags. $^{2}$ At that time, the majority of members of this global organization were from Europe and the recommendation was completed by consensus:

The efficiency of the transceiver in combination with probe and shovel, and of airbag systems has been proven.

Additionally, the textbook used by the WMS Diploma in Mountain Medicine course omits mention of airbags altogether. ${ }^{3}$

The 3 main North American avalanche organizationsthe American Avalanche Association (A3), Canadian Avalanche Association (CAA), and American Institute for Avalanche Research and Education (AIARE)-have no formal recommendation for airbag use on their websites or in their publications, as confirmed by published information, websites, and personal communication with the 3 agencies. For the A3, airbags are part of the core curriculum for only 1 course, titled Avalanche Rescue; this is 1 of 5 courses that range from basic to advanced. For the AIARE, airbags are considered "additional safety equipment" in the student manual. ${ }^{4}$ In the CAA risk handbook, airbags are mentioned only once in discussion of risk statistics. ${ }^{5}$

\section{Overview of Literature}

Like many topics in wilderness and mountain medicine, the literature on avalanche airbags is sparse. Several key studies regarding airbags will be highlighted. One study found that airbags reduced mortality from 19 to $3 \% .^{6}$ Another study reported on 245 accidents involving 424 injuries and a $19 \%$ overall mortality rate. ${ }^{7}$ A subset of the data looked at 66 accidents with both airbag users and non-airbag users. In this subset, all noncritically buried fatalities were due to trauma. Mortality reduction of critical burials decreased from 34 to $11 \%$ with use of an airbag. ${ }^{7}$ (Critical is defined as the head being under snow and breathing impaired; noncritical is defined as an unobstructed airway.) Of note, airbag deployment failure and device failure were found to be significant in both studies. One study found a $20 \%$ failure rate (7 of 35 participants), ${ }^{6}$ and another found a $20 \%$ failure rate (61 of 307 participants) $^{7}$; this was due to user error, device failure, or device damage during avalanche.

A third study used a series of planned avalanches to test dummies equipped with and without airbags. ${ }^{8}$ Of the 5 dummies without airbags, burial depth was a mean of $43 \mathrm{~cm}$, and only 1 of 5 was visible from the surface. In contrast, of 14 dummies with airbags, burial depth was a mean of $15 \mathrm{~cm}$, with all 14 visible from the surface. This study also found that among the 14 airbag dummies, the head was visible for all but 5 and the airway was less than $10 \mathrm{~cm}$ below the surface for all but 2 .

Similarly, the literature on transceivers is limited and outdated; most studies on transceivers were conducted before widespread use of modern technology, including digital processing and 3 antennas. Nonetheless, avalanche transceivers have been shown to reduce mortality. One study showed transceivers reduced time from burial to companion rescue from 120 to $30 \mathrm{~min}$ but did not yield a significant reduction in mortality. ${ }^{6}$ Another showed that burial time was decreased from 102 to $30 \mathrm{~min}$ and mortality from 68 to $54 \%$ with use of a transceiver. ${ }^{9}$ A third study confirmed burial time reduction from 125 to 25 min using a transceiver and a mortality risk reduction from 70 to $55 \%$. $^{10}$

\section{Barriers}

The important messages from these studies are twofold. First, airbags are successful at decreasing mortality from avalanches, mostly in preventing critical burials. As with any device, user error and equipment failure are substantial problems. Second, airbags' mortality-rate reductions are similar to transceivers, with the limitations discussed previously. However, airbags help prevent burial, whereas transceivers are employed once a person is caught in an avalanche and buried.

Despite these studies, airbags are still not universally adopted as standard avalanche safety equipment. Several barriers exist to universal use of airbags. 


\section{AVAILABILITY AND EQUIPMENT CHALLENGES}

Airbags can be limited in availability in some regions. This has probably made adoption slow. The availability of canisters, which must be shipped as hazardous material in the United States, is limited. Refilling canisters, which can be done at a retail shop or at home with a highpressure pump, is also difficult, especially for users who live in rural areas with no access to authorized sales and refilling vendors. Sharing canisters among groups with different brands and models is difficult, as is carrying extra canisters. Fan airbags need to be charged; thus, access to power is needed. Both canister and fan airbags can be affected by cold temperatures. For both fan and canister models, electronic and mechanical parts can fail.

\section{SIZE AND WEIGHT}

Airbags are significantly heavier and bulkier than standard, non-airbag backpacks. Whereas an average backpack can weigh as little as $0.5 \mathrm{~kg}$, the lightest airbags are still around $2 \mathrm{~kg}$. This is a significant issue for the weightconscious mountain traveler who may have a full backpack of mountaineering and rescue equipment.

\section{COST}

Airbags are significantly more costly than standard packs. A backcountry ski backpack can cost as little as $\$ 100$ USD, whereas airbag backpacks range from $\$ 700$ to > $\$ 1000$ USD.

\section{TRAINING}

Airbags require additional training. For recreational enthusiasts, this means another device to learn how to use and practice with. For professionals, this adds extra training to an already complex mountain safety program. For avalanche schools, this adds more training and higher cost to have all students equipped with airbags.

\section{COMMUNITY USE}

The promotion of airbags in local communities via equipment retailers, social media, and professional organizations can play a role. If a community has an important educational organization or mountain shop that promotes airbag use, airbags may be adopted more readily than if the community has no local promotion or awareness.

\section{RISK TOLERANCE}

Airbags may increase risk tolerance for users and thus may be both a deterrent and a perceived benefit for users. Two studies suggest some airbag users may take more risks when traveling in avalanche terrain. ${ }^{11,12}$

\section{GUIDELINES}

Professional societies and associations, in scientific and lay publications and in textbooks, have neither recommended airbags as standard equipment nor provided much education or guidance about them in curricula. This likely plays a large role in the lack of universal use.

\section{Knowledge Gaps}

Aside from preventing burial, other questions worth considering are discussed in the following. These issues are important because they may contribute to lack of adoption of airbags.

\section{DOES BALLOON SIZE MATTER FOR FLOTATION?}

A smaller balloon may be less expensive and lighter and thus more likely to be used. The standard is a $170-\mathrm{L}$ balloon. A larger balloon may be more effective at keeping a user atop avalanche debris, but it makes weight and cost higher and design more difficult, including the need for a larger fan or canister. Similarly, a smaller balloon maybe be less expensive and lighter, but it may not work as well to lessen morbidity and mortality.

\section{DO AIRBAGS PROTECT FROM TRAUMA?}

Airbag use may be encouraged if data demonstrate protection from trauma, considering trauma accounts for $25 \%$ of fatalities. ${ }^{2}$ More studies could address this. Anecdotal cases suggest that a 170-L balloon does offer some degree of trauma protection for the head, neck, and torso. The WMS clinical practice guidelines did not reach a conclusion on this issue. ${ }^{1}$ Similarly, balloons that extend above and wrap around the head and neck may protect one better than those that do not, but no data exist on this issue.

\section{DO AIRBAGS CREATE AN AIR POCKET AND/OR PROTECT THE AIRWAY TO DELAY ASPHYXIA?}

If airbags can help prevent asphyxia, as with trauma, they may be adopted more readily. We know that air pockets and patent airways help prolong survival. ${ }^{13-15}$ One brand and model of fan airbag deflates after inflation. In a recent study, researchers buried 12 volunteers with an airbagcreated air pocket and measured oxygen saturation, end tidal carbon dioxide, heart rate, and respiratory rate. ${ }^{16}$ Eleven volunteers were observed for $60 \mathrm{~min}$. The burial experiment was ended for the 12th volunteer owing to an increased heart rate, increased end tidal carbon dioxide, and anxiety. Participants with a simulated air pocket created by an airbag were able to move their head an estimated $11 \mathrm{~cm}$ forward and $7 \mathrm{~cm}$ backward. 
The study concluded that it is possible that an air pocket from a deflated airbag could prolong survival. Again, more studies are needed to address this question.

\section{SHOULD CANISTERS BE STANDARDIZED?}

If canisters and actuation systems were standardized, use of airbags could increase because users would be able to more freely trade canisters. Canisters are available in a variety of sizes, proprietary actuation systems, and gasses. Some companies use different canisters for North American and European versions of their airbags owing to regulations regarding shipping and importing compressed gas canisters.

\section{Conclusions}

Airbags have been shown to be effective at saving lives. At first glance, they seem to be equal to transceivers in reducing mortality. Yet studies on airbags are limited, and studies on transceivers are outdated. Even so, with both transceivers and airbags, the absolute mortality rate reduction is small. Notwithstanding these limitations, airbags clearly save lives but are not yet considered standard avalanche safety equipment owing to barriers as described above. Some of these issues can be addressed. As with many products, as demand increases, availability may increase. Cost, weight, and size are largely dependent on the market and the manufacturer, but airbags continue to become less expensive and lighter.

Other difficulties can be addressed largely with education programs. This includes local organizations and retailers to promote use, avalanche education schools to promote training, and professional societies and associations to highlight importance.

Based on the literature, if one wants to maximize safety in avalanche terrain, one should use an airbag in addition to other standard safety tools. An airbag is an effective tool at reducing mortality and is the only tool that helps prevent burial.

Financial/Material Support: None.

Disclosures: None.

\section{References}

1. Van Tilburg CS, Grissom CK, Zafren K, McIntosh S, Radwin MI, Paal P, et al. Wilderness Medical Society practice guidelines for prevention and management of avalanche and nonavalanche snow burial accidents. Wilderness Environ Med. 2017;28(1):23-42.

2. Avalanche Rescue, Terrestrial Rescue, and Medical Commissions. Avalanche safety devices and systems. In: Proceedings International Commission for Alpine Rescue.
Kranjska Gora, Slovenia; 2016;1. Available at: http://www. alpine-rescue.org/ikar-cisa/documents/2007/20061014Statement-Avalanche-Safety-Dev-E.pdf. Accessed May $15,2021$.

3. Hutchinson J. Avalanche fundamentals. In: Rodway GW, Weber DC, McIntosh SE, eds. Avalanche Fundamentals in Mountain Medicine \& Technical Rescue. Herefordshire, UK: Carreg; 2016:398-414.

4. Zacharias C. The Student Handbook for The AIARE Risk Management Framework. Vail: American Institute for Avalanche Research and Education; 2018.

5. Campbell C, Conger S, Gould B, Haegeli P, Jamieson B, Statham G, eds. Avalanche Association Technical Aspects of Snow Avalanche Risk Management. Revelstoke, Canada: Canadian Avalanche Association; 2016.

6. Brugger H, Etter HJ, Zweifel B, Mair P, Hohlrieder M, Ellerton J, et al. The impact of avalanche rescue devices on survival. Resuscitation. 2007;75(3):476-83.

7. Haegeli P, Falk M, Procter E, Zweifel B, Jarry F, Logan S, et al. The effectiveness of avalanche airbags. Resuscitation. 2014;85(9):1197-203.

8. Meier L, Harvey S. How effective are avalanche airbags? Field tests of avalanche safety equipment. In: Proceedings International Snow Science Workshop. Anchorage; 2012: 756-763. Available at https://arc.lib.montana.edu/snow-science/objects/ issw-2012-756-763.pdf. Accessed May 15, 2021.

9. Brugger H, Durrer B, Adler-Kastner L, Falk M, Tschirky F. Field management of avalanche victims. Resuscitation. 2001;51(1):7-15.

10. Hohlrieder M, Mair P, Wuertl W, Brugger H. The impact of avalanche transceivers on mortality from avalanche accidents. High Alt Med Biol. 2005;6(1):72-7.

11. Haegeli P, Rupf R, Karlen B. Do avalanche airbags lead to riskier choices in the backcountry? In: Proceedings International Snow Science Workshop. Innsbruck, Austria; 2018:1293-1297.

12. Christie S. Avalanche airbag survey: A US perspective. In: Proceedings International Snow Science Workshop. Anchorage; 2012:361-362 Available at https://arc.lib. montana.edu/snow-science/objects/issw-2012-361-362.pdf. Accessed May 15, 2021.

13. Grissom CK, Radwin MI, Harmston CH, Hirshberg EL, Crowley TJ. Respiration during snow burial using an artificial air pocket. JAMA. 2000;283(17):2266-71.

14. Brugger H, Sumann G, Meister R, Adler-Kastner L, Mair P, Gunga HC, et al. Hypoxia and hypercapnia during respiration into an artificial air pocket in snow: implications for avalanche survival. Resuscitation. 2003;58(1):81-8.

15. Strapazzon G, Brugger H, Paal P, Brown D. Reconsidering the air pocket around mouth and nose as a positive outcome predictor in completely buried avalanche victims. Resuscitation. 2020;152:208-9.

16. McIntosh SE, Little CE, Seibert TD, Polukoff NE, Grissom CK. Avalanche airbag post-burial active deflation The ability to create an air pocket to delay asphyxiation and prolong survival. Resuscitation. 2020;146:155-60. 